\title{
Super green rice in China (Abstract)
}

\section{Yongzhong Xing}

National Key Lab of Crop Genetic improvement, Huahzong Agricultural University, 430070, Wuhan China

Corresponding author: yzxing@ mail.hzau.edu.cn

\begin{abstract}
Rice production in China has abused chemical fertilizers and pesticides for a long time, causing serious environmental pollution. In response to this major social issue, Chinese scientists proposed the second green revolution concept of "less investment, more output and better environment" at the end of the 20th century. In 2007, Chinese scientists proposed the concept of green super rice with the characters of "fewer pesticides, less chemical fertilizers, water saving and drought resistance, high yield and superior quality, and comfortable environment ". In 2010 and 2014, Huazhong Agricultural University as the coordinator hosted the key project of 863 Program of Ministry of Science and Technology "cultivation of new green super rice varieties". They suggested that Green super rice cultivation should divided into three phases. The first phase is to cultivate rice varieties resistant to many major diseases and pests, and thereby without spraying pesticides. The second phase is to cultivate varieties with a higher utilization efficiency and absorption efficiency of water and nitrogen and phosphorus fertilizers, thereby reducing the use of chemical fertilizers. The third phase is to cultivate a significantly enhanced drought resistance of new rice varieties, to achieve the goal of drought and water conservation through biotechnology, molecular marker-assisted selection and genome-wide selection technology. After the three-phase goal is reached, rice production will eventually achieve "less pesticides, less chemical fertilizers, water saving and drought resistance, high yield and super quality". Over the past 20 years, several reference genome sequences have been released one after another, which promotes significant progress of rice functional genomics. Special resources have been identified by establishing a rice core collection. For example, resources are resistance to pests and diseases, low nitrogen and phosphorus and drought stress, or show good performance for other target traits. Dozens of genes for grain yield, quality, plant architecture, biotic stress and abiotic stress have been isolated, which provide gene resources for the cultivation of green super rice through genome-wide selection to pyramid different good genes in the background of high-yielding varieties. More than 20 varieties (combinations) have been released at provincial or national levels. About 70 lines with green traits have been selected to adapt to different rice growing areas. Super green rice new varieties have been grown 1.4 million hectares, and reduced amounts of pesticides, fertilizers and other labor inputs, saved irrigation water, and brought significant social and economic benefits, significant ecological and environmental benefits.
\end{abstract}

Key words: China, varieties of super green rice, diseases and pests rice, drought resistance, rice functional genomics, genome-wide selection. 
